
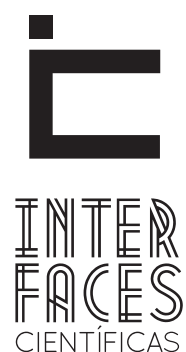

EDUCAÇÃO

ISSN IMPRESSO 2316-333X

ISSN ELETRÔNICO 2316-3828

\title{
OS INTELECTUAIS E A CONSTRUÇ̃̃o DA ESFERA PÚBLICA LITERÁRIA EM PORTUGAL: 0 PAPEL DE LUIS ANTÓNIO VERNEY E SEU VERDADEIRO MÉTODO DE ESTUDAR [1746] ${ }^{1}$
}

César de Alencar Arnaut de Toledo ${ }^{2}$

\section{RESUMO}

O objetivo deste artigo é analisar o papel dos intelectuais na formação da esfera pública literária em Portugal no século XVIII e sua relação com a educação. Para tanto, será considerada a trajetória intelectual do estrangeirado português Luis António Verney (1713-1792) e sua polêmica obra, o conjunto de cartas intitulado Verdadeiro Método de Estudar, publicada em 1746 . O caminho deste texto será apresentar uma discussão acerca do papel do intelectual no século XVIII, no contexto do Iluminis-
Vanessa Campos Mariano Rucktadter ${ }^{3}$

mo, em especial, do Iluminismo em Portugal. Esta análise, também, perpassa uma discussão sobre o conceito de opinião pública, bem como o diálogo estabelecido entre Verney e demais intelectuais portugueses do século XVIII.

\section{PALAVRAS-CHAVE}

História da Educação. Século XVIII. Portugal. Esfera Pública Literária. Intelectuais. Luis António Verney.

1. As reflexões e análises aqui apresentadas são resultado da pesquisa desenvolvida no programa de Pós-Graduação em Educação da Universidade Estadual de Maringá, e contou com apoio financeiro da Coordenação de Aperfeiçoamento de Pessoal em Nível Superior (CAPES). A tese de doutorado intitulada Luis António Verney e o Projeto Pedagógico Modernizador do Reino Português: uma análise do Verdadeiro Método de Estudar (1746) foi defendida em 29 de outubro de 2012 


\section{ABSTRACT}

The objective of this article is to analyze the role of the intellectuals in the formation of the literary public sphere in Portugal in the eighteenth century and its relations with the education. For this, it will be considered the intellectual trajectory of the Portuguese foreigner Luis Antonio Verney (1713-1792) and his polemic work, the set of letters called True Method of Studying (Verdadeiro Método de Estudar), published in 1746 . The path of this text will be to present a discussion about the intellectual part in the eighteenth century, in the Enlightenment context, specially the

\section{RESUMEN}

El objetivo de este artículo es analizar el papel de los intelectuales en la formación de la esfera pública literaria en Portugal en el siglo XVIII, y su relación con la educación. Por lo tanto, será considerada la trayectoria intelectual del extranjero portugués Luis António Verney (1713-1792) y su polémica obra, el conjunto de cartas titulado Verdadeiro Método de Estudarpublicada en 1746. El enfoque de este texto será encaminar una discusión acerca del papel del intelectual en el siglo XVIII, con el contexto del Ilu-
Enlightenment in Portugal. This analysis also goes through a discussion of the concept of public opinion as well as the dialogue between Verney and other Portuguese intellectuals of the eighteenth century.

\section{KEYWORDS}

History of Education. Eighteenth Century. Portugal. Literary Public Sphere. Intellectuals. Luis Antonio Verney.

minismo, en especial, del Iluminismo en Portugal. Este análisis también sobrepasa la discusión sobre el concepto de opinión pública, bien cono el diálogo establecido entre Verney e demás intelectuales portugueses del siglo XVIII.

\section{PALABRAS CLAVE}

Historia de La Educación. Siglo XVIII. Portugal. Esfera Pública Literaria. Intelectuales. Luis António Verney. 


\section{INTRODUÇÃO}

Este texto objetiva analisar a construção de uma esfera pública literária e da opinião pública em Portugal no século XVIII em sua relação com a educação. Para tanto será considerada a trajetória de Luis António Verney (1713-1792) como intelectual que propôs ampla reforma da educação em todos os níveis em Portugal. Seu projeto modernizador para o reino português foi publicado anonimamente em 1746 em um conjunto epistolar intitulado Verdadeiro Método de Estudar. Há indícios de que Verney tenha publicado a obra de modo intencional para formar um público desejoso das reformas na sociedade portuguesa via educação (DE ANDRADE, 1966). Cabe afirmar: além de um público esclarecido, Verney tinha o intuito do convencimento de seus pares, os padres oratorianos e que já possuíam prestígio em Portugal no reinado de Dom João V (1707-1750), especialmente na educação.

Nesse sentido, esta discussão se pauta pelo encaminhamento metodológico feito por Milton Meira do Nascimento (1989), ao analisar um grupo de intelectuais na França e seu papel na revolução de 1789, conhecido como Círculo Social. Ele analisa em sua obra em que medida as ideias desse grupo circularam na França pré-revolucionária e possibilitaram a formação de um público maior de pessoas desejosas de uma mudança na sociedade. O prefácio de seu livro conta com a contribuição da Professora Marilena Chauí (1989) no que se refere à discussão sobre a formação da opinião pública e seu papel nas mudanças sociais ou nos projetos de mudança.

Uma vez que Verney se circunscreve no contexto dos autores que Nascimento (1989) analisa como os primeiros a discutirem o papel dos intelectuais na formação da opinião pública será aqui considerada a análise feita por ele, mais em relação ao encaminhamento metodológico que propriamente ao conteúdo discutido em seu livro.
Essa discussão, também, dialoga com autores da área de educação que analisam o iluminismo português, especialmente a professora Carlota Boto (2010), que tem se dedicado a analisar o iluminismo português e as reformas dos estudos em Portugal e seu legado, bem como as professoras Ana Cristina Araújo (2003) e Thaís Nívea Lima e Fonseca (2009), no intuito de circunscrever a análise e debate nas discussões sistemáticas e no esforço de um grupo de pesquisadores brasileiros e portugueses em analisar um período ainda pouco estudado pelos historiadores da educação brasileira, seja ele o século XVIII.

Os filósofos do século XVIII, não desconsiderando suas particularidades e contextos, apresentaram um discurso comum: a esperança de um homem melhor, e, consequentemente uma sociedade melhor. A tarefa de melhorar o homem caberia à educação, e a consequência de tal intento seria o progresso humano. Foi criada uma expectativa de um progresso contínuo e irreversível. 0 papel do intelectual nesse processo era o de educador, o que poderia denominar de intelectual pedagogo. Os filósofos, os homens da razão, dessa maneira, teriam a tarefa de educar os homens. Todavia, não significava educar a população em geral, ou ainda, a defesa da educação do povo, de todos. Tratava-se da tarefa de educar principalmente o governo dos homens.

A base do projeto de desenvolvimento e progresso implicava que se atribuísse um papel fundamental à ação esclarecida dos homens ao longo da história humana. Nesse sentido, os filósofos se apresentavam como profetas laicos e educadores da humanidade (ARAÚJO, 2003).

Havia, também, no século XVIII uma preocupação em conhecer, saber, para prover o futuro. Inseriamse nessa perspectiva do intelectual pedagogo, com a tarefa de educar os homens, alguns autores do con- 
texto iluminista português. Ribeiro Sanches (2003, p. 23), por exemplo, alertava que “[...] é da obrigação do juízo humano prever tudo, e conhecer as causas das desordens presentes, para evitá-las, ou suprimi-las pelo discurso do tempo". Era necessário identificar no presente as causas das desordens para evitá-las ou até chegar a suprimi-las no futuro, acreditando na perfectibilidade humana, isto é, na capacidade do homem de melhorar a si mesmo por meio do esclarecimento, da educação.

Os intelectuais no século XVIII se colocavam na condição de preceptores do povo a fim de esclarecê-los com as luzes da razão; acreditavam possuir a missão de guiá-lo na derrubada da tirania para que fosse exercida a soberania. Esse processo ocorreria como vigilância pública, de uma cobrança e pressão de um maior número de pessoas (CHAUÍ, 1989). O papel do intelectual nesse contexto passou a ser, mais que uma questão de elaboração teórica, uma questão de ação política. Dessa maneira, mais que elaborar projetos, o intelectual pretendia que suas ideias se tornassem efetivas pelas mãos daqueles que estavam no poder, os homens de governo.

O surgimento da concepção moderna de opinião pública se deu ao longo dos séculos XVII e XVIII. Ela pode ser entendida como força racional capaz de exercer pressão sobre os indivíduos, instância julgadora a exigir um processo de esclarecimento e de formação do próprio público, por meio dos intelectuais, considerados os portadores das Luzes e da Palavra regeneradora:

Se na tradição filosófica, o conceito de opinião sempre fora relegado à condição de sombra perturbadora da verdade, obstáculo à razão, sistema do medo e do preconceito cristalizado nos costumes, sobretudo sob a ação dos poderes eclesiásticos, no final do século XVIII, fazendo-se opinião pública, passa a ser encarada positivamente. Tida, antes como efêmera e volúvel, reino duvidoso da moda, torna-se agora, estabilizadora dos costumes e da moral, transpondo a moda para o reino da verdade. (CHAUI, 1989, p.16).
É válido considerar que Verney e sua proposta de um verdadeiro método se inserem nesse intuito dos intelectuais esclarecidos de formar uma opinião pública. 0 intuito de levar sua verdade a se tornar universal, por Verney, pode explicar a razão para que a obra fosse publicada anonimamente, e para que não admitisse sua autoria, sobretudo após o intenso debate que seguiu a publicação.

Formar a opinião pública fazia parte dos esforços que se iniciaram no final do XVII, e se intensificaram ao longo do "Século das Luzes" na Europa, de grupos de intelectuais para que seus discursos fossem aceitos e assimilados pelo público esclarecido, bem como por seus pares. A opinião pública seria o encontro da razão e um maior número de pessoas esclarecidas, e também, como uma verdade a ser defendida. Seu poder dependeria da sua capacidade de se impor aos homens no poder (CHAUÍ, 1989).

Até o século XVIII a tradição filosófica considerou opinião como algo falso. Era utilizada com o sentido de oposição à ciência (NASCIMENTO, 1989). A partir do século XVIII houve a ampliação de espaços de convívio social, e, considerando que o mundo das ideias possui uma relação estreita com as práticas sociais, possibilitou a formação de uma esfera pública literária. A construção dessa esfera pública possibilitou um espaço público de crítica, que se ampliou a partir de novos espaços de sociabilidade e de novas práticas sociais, como por exemplo, o ato de frequentar cafés, salões e mesmo a formação de academias científicas e literárias. (HABERMAS, 2003).

No século XVIII pode-se considerar que a opinião pública já era reconhecida como uma forma racional capaz de exercer uma pressão sobre os indivíduos, e entendida pelos intelectuais iluministas como processo de esclarecimento de formação do público, que deve tomar o lugar dos preconceitos existentes. Pode-se constatar essa noção de opinião pública iluminista, por exemplo, no verbete da famosa Encyclopédie, organizada e dirigida por Denis Diderot (1713-1784) e 
Jean Le Rond d'Alembert (1717-1783). Nela, o verbete opinião, de autoria desconhecida, aparece como crença fundada sobre um motivo provável, como um julgamento duvidoso e incerto do espírito ${ }^{3}$. 0 grande tema do século XVIII era eliminar preconceitos, superstições, considerados os maiores inimigos do progresso das ciências (NASCIMENTO, 1989).

A fim de superar as superstições, que impediriam o progresso das ciências, emergiu no século das luzes a esperança de um homem melhor, o que seria possível por meio "do ensino dos valores e dos progressos realizados pela cultura ocidental” (ARAÚJO, 2003, p. 51).

0 principal inimigo da Filosofia nesse contexto não era a dúvida, mas o dogma, a autoridade e o preconceito. Esta era a questão central no debate entre "antigos e modernos". Ao discutir o preconceito da autoridade em sua carta décima, sobre os estudos de Física, Verney questionou o argumento: "Que importa que Aristóteles, ou todos os outros Filósofos da Grécia, dissessem que o Ar era leve, se estou vendo experiências que provam que é pesado?” (VERNEY, 1950b, v.3, p. 193).

Em Portugal houve um intenso movimento de filósofos, que se apresentavam na condição de profetas laicos e educadores da humanidade, no sentido de iluminar a nação. Nesse contexto, quem deu voz à opinião pública foi uma elite esclarecida. Os assuntos relativos à prática e à experiência científica extrapolaram os muros das universidades e colégios. Os mais variados assuntos relativos às ciências passaram a ser intensamente discutidos nos círculos sociais nobres e burgueses:

Na transição dos séculos XVII para o século XVIII, as redes de contacto, institucionais e/ou informais, de sábios, eruditos e filósofos, alteraram-se. Arautos de uma nova visão do mundo, estes homens de razão entregaram-se à busca da verdade com disciplina e sentido de missão. Usam uma linguagem própria, recorrem a métodos de verificação idênticos e partilham

3. Verbete original disponível em: http://artflx.uchicago.edu/images/encyclopedie/V11/ENC_11-506.jpeg. Consulta realizada em 17 set. 2012. os resultados das suas experiências. As suas ideias e descobertas encontram eco fora dos circuitos tradicionais de informação, conservados, durante séculos a fio, à sombra dos colégios e das universidades. (ARAÚJO, 2003, p. 13).

Naquele momento de intenso debate e circulação dos saberes, e do sentido de missão de que estavam imbuídos os intelectuais, apareceu a defesa de que a educação seria a principal via de modernização da sociedade. É importante considerar que as múltiplas vozes do iluminismo português não formavam unanimidade em alguns aspectos da educação, mas todos a defendiam como via central de reformas:

Em Portugal, os entendimentos e as proposições dos iluministas acerca desses princípios gerais não foram unívocos, variando conforme a valorização dos ensinos público e particular, a educação para as mulheres ou o grau de intervenção do Estado na educação, por exemplo. (FONSECA, 2009, p. 24)

Verney deve ser analisado em sua relação com os outros estrangeirados que se ocuparam em pensar projetos de reformas modernizadoras para Portugal via reforma dos métodos de ensino. Destacaram-se três pensadores que, juntamente com Verney, preocuparam-se com a renovação dos métodos de ensino e a modernização do reino português no século XVIII: Martinho de Mendonça de Pina e Proença (16931743), Dom Luís da Cunha (1662-1749) e Antonio Nunes Ribeiro Sanches (1699-1783).

O primeiro, Pina e Proença, foi o responsável pela divulgação do pensamento de Locke, Fénelon e Rollin em Portugal e a sua principal obra foram os Apontamentos para a educação de um menino nobre (1734). Foi membro da Academia dos Anônimos e da Academia Real de História. Assumiu cargos administrativos no reino na Torre do Tombo, na Real Biblioteca e ainda no Conselho Ultramarino. Foi, também, Governador da capitania de Minas Gerais entre 1736 e 1737. Dentre suas ideias sobre educação, destaca-se a defesa da educação preceptoral para a nobreza separada das escolas públicas. 
Além disso, defendia o ensino de uma moral civil, pois defendia a civilidade para formar o leal servidor do rei (FONSECA, 2009). Aproximava-se da defesa que Verney fazia do ensino de Ética Particular para ensinar os homens a conhecer seus deveres na sociedade civil. (VERNEY, 1950, v. 3).

O Testamento Político de D. Luís da Cunha é um importante documento para compreender Portugal no século XVIII. Assim como Verney, D. Luís da Cunha era um estrangeirado, que viveu em Londres, exercendo a atividade de embaixador. Defendia o fortalecimento do papel do rei, que deveria, para tanto, curar os males da sociedade portuguesa. Nessa obra, uma carta ao então príncipe D. José, escrita pouco antes de ele assumir o trono, D. Luís da Cunha sugere alguns nomes para assumir o cargo de principal ministro do reino. Dentre eles, dá destaque ao nome de Sebastião José de Carvalho e Melo. Foi um dos idealizadores de uma modernização econômica em Portugal, e, para tanto, identificou algumas "sangrias" que impediam o desenvolvimento. Percebeu-se a preocupação de Cunha em igualar Portugal aos demais reinos europeus, e, para tanto, ele identificou os principais males, ou, conforme nominou "sangrias", que seriam entraves ao desenvolvimento português.

Dentre as quatro apontadas, duas se destacam. Primeiro, o numeroso contingente de homens e mulheres que procuravam o convento e nele se enclausuravam, sem serem úteis à Pátria, uma vez que não procriavam e tampouco trabalhavam. Segundo, o envio de homens aos domínios além-mar, principalmente às Índias e ao Brasil. Para ele era necessário formar indivíduos úteis à nova conformação social, e que não deveriam aspirar somente a vida religiosa ou se aventurar nas novas colônias, mas antes, ajudar a construir Portugal, nos moldes do desenvolvimento capitalista (CUNHA, 1976). De certo modo, ao defender a formação do homem virtuoso qualquer que fosse sua posição na sociedade, Verney não defendia necessariamente a vida religiosa para todos.
O terceiro, Ribeiro Sanches, escreveu as Cartas sobre a educação da mocidade, publicado em 1760. Pode-se perceber em sua obra a diretriz reformista e pedagogista que marcou o pensamento iluminista português (FONSECA, 2009). Defendia a educação para o bem público - res publica - em uma perspectiva do contrato social. Ainda, foi defensor da escola a cargo do Estado para fins normatizadores.

Além disso, a elite, para ele, deveria aspirar não somente ser cavalheiro ou membro do clero (RIBEIRO SANCHES, 2003). O autor tinha uma base cristã, como os outros iluministas portugueses, e não desconsiderava, como a maioria dos iluministas portugueses, inclusive Verney, a importância da educação cristã com um objetivo moral (VERNEY, 1950, v. 3). Todavia, essa educação moral, ainda que cristã, deveria ficar a cargo do Estado, não da Igreja. Dessa forma, pode-se afirmar que tinha uma visão anticlerical, mas não anticristã (FONSECA, 2009). Para ele, a formação cristã seria a base da reforma da sociedade portuguesa, e a reforma em todo o reino deveria visar a formação de jovens úteis à pátria. Diferente de outros pensadores portugueses advogava a ideia do ensino separado para as diferentes classes sociais, o que considerava fundamental na manutenção do poder do Estado. Não havia em seu pensamento a defesa do ensino universal, e o exemplo a ser seguido por todas as pessoas deveria ser o das classes dominantes.

Verney, também, defendia, por exemplo, em sua carta sobre os estudos de gramática portuguesa, que o português ensinado fosse simplificado, e que fossem usadas somente as palavras utilizadas por homens cultos. Os dicionários deveriam ser, também, simplificados, e sugeria a exclusão do grande número de palavras plebeias (VERNEY, 1949 , v. 1). Assim como Verney, passou a ser perseguido pelo Marquês de Pombal, e teve exílio na Rússia, onde se tornou o médico da czarina Ana Ivanovna (1693-1740). 
O século XVIII foi, também, um período de ampliação do debate das descobertas no âmbito civil, por meio de sociedades ou academias científicas e literárias. Houve o estímulo à circulação de livros e de notícias, bem como ao intercâmbio das descobertas. Nesse sentido, houve uma ampliação do debate de ideias e difusão do conhecimento que ultrapassou o meio restrito das escolas, colégios e universidades e passou a se colocar "[...] à disposição dos príncipes e dos Estados, em prol do progresso e do bem-estar social; permeiam o mérito, e agenciam a promoção de carreiras na esfera da sociedade civil” (ARAÚJO, 2003, p. 13).

Verney atribui a essas academias a produção de um saber moderno, pois era um saber que considerava a observação e a experiência. Além disso, produziam um conhecimento legitimado pelo grupo. Ao indicar a bibliografia para os estudos de Geometria e Aritmética, essenciais à compreensão da Física, Verney sugeriu, além dos livros newtonianos, as coleções publicadas por academias científicas:

[...] ali não há perigo que aleguem uma coisa falsa por verdadeira, porque, primeiro que se publiquem, são vistas e revistas, e aprovadas pelo corpo da Academia. Coitadinho deles se alegassem falso: sairiam logo mil críticas que os desasariam. (VERNEY, 1950, v.3, p. 204).

Contudo, sobre essas academias em Portugal ironizou Verney, sobretudo a Academia de História. A partir da leitura das obras históricas das coleções dessa academia conclui que ${ }^{4}$ :

[...] na dita Academia se tem adoptado tantas fábulas históricas de que o mundo erudito se ri, porque os que as adoptam não sabem que coisa é Arte Crítica e Hermenêutica, que são duas partes da Lógica Moderna, e os fundamentos da história, como advirto na minha Lógica. (VERNEY, 1753, p. 52-53)

Verney sabia que precisava do apoio régio para que esse saber fosse difundido:

4. Colecção dos Documentos e Memórias da Academia Real da História Portuguesa, que nos anos de 1721 a 1736 se compuseram e se imprimiram por ordem de seus censores. (CURADO; CURADO, 2008, p. 52).
[...] grande serviço fazem ao público os Princípes que fundam, dotam e protegem semelhantes Academias, e remuneram os que assinalam nestes estudos! Fazem tão grande utilidade ao público, que não há louvor, nem agradecimento, que os iguale. (VERNEY, 1950, v.3, p. 204).

Precisava duplamente do apoio da Coroa, primeiro, pelo apoio financeiro. Segundo, para que sua reforma se tornasse oficial:

Para levar a cabo a missão de iluminar o País, a munificência Régia tornava-se necessária, não só pelo aspecto mecenático de que empresas desta ordem não prescindem, como ainda pelo motivo de intentar a reforma de ensino oficial. (DE ANDRADE, 1966, p. XI).

Assim, pode-se afirmar que em Portugal no século XVIII se formava um espaço de debates, uma esfera literária, e Verney, apesar de ter vivido parte de sua vida na Itália, se inseria nesse contexto de crítica e de busca da verdade por meio do método científico. Além disso, colocava-se à disposição do Estado português, principalmente ao propor um projeto modernizador para o reino português que tinha como corolário a reforma dos métodos de estudos.

Em cada uma das dezesseis cartas que compõe sua principal obra, o Verdadeiro Método de Estudar, apresenta uma crítica à organização dos estudos em Portugal, aos métodos utilizados, sobretudo pelos padres jesuítas. Tratava-se de um plano de reformulação na normatização dos estudos para servirem à Igreja e à República, e, atender, dessa maneira, às modificações que urgiam serem feitas na sociedade portuguesa para sua inserção econômica, política e cultural no mundo europeu das Luzes. Com esse intuito Luis António Verney escreveu suas cartas, seus compêndios e dedicou sua vida na tarefa de "iluminar" a nação portuguesa. 


\section{REFERÊNCIAS}

ARAÚJO, A. C. A Cultura das Luzes em Portugal: temas e problemas. Lisboa: Horizonte, 2003.

BOTO, C. A dimensão iluminista da reforma pombalina dos estudos: das primeiras letras à universidade. Revista Brasileira de Educação, v.15, n.44. Rio de Janeiro: ANPED, maio/ago. 2010, p. 282-299.

CHAUÍ, M. Prefácio. In: NASCIMENTO, M. M. do. Opinião Pública e Revolução. São Paulo: Nova Stella, EDUSP, 1989, p. 13-19.

CUNHA, Luís (Dom). Testamento político de D. Luis da Cunha. São Paulo: Alfa-Ômega, 1976.

Curado, A. L.; Curado, M. Prefácio. Verney, Luis Antonio. Cartas Italianas. Lisboa: Sílabo, 2008, p. 9-29.

DE ANDRADE, António Alberto. Verney e a cultura do seu tempo. Coimbra: Acta Universitatis Conimbrigensis, 1966.

FONSECA, Thais Nivia de Lima e. Letras, ofícios e bons costumes: civilidade, ordem e sociabilidades na América Portuguesa. Belo Horizonte: Autêntica, 2009.
NASCIMENTO, M. M. do. Opinião Pública e Revolução. São Paulo: Nova Stella, EDUSP, 1989.

HABERMAS, J. Mudança estrutural da esfera pública: investigações quanto a uma categoria da sociedade burguesa. Trad. Flávio R. Kothe. 2.ed. Rio de Janeiro: Tempo Brasileiro, 2003.

OPINIÃO (Verbete) Disponível em: <http://artflx.uchicago.edu/images/encyclopedie/V11/ENC_11-506. jpeg>. Acesso em: 17 set. 2012.

\section{RIBEIRO SANCHES, A. Cartas sobre a educação da}

Mocidade. Universidade da Beira Interior Covilhã - Portugal, 2003. Disponível em: <http://www.estudosjudaicos.ubi.pt/rsanches_obras/cartas_educacao_mocidade.pdf>. Acesso em: 9 abr. 2012.

VERNEY, L. A. Carta ao Amigo do Coração. (1753). In: DE ANDRADE, António Alberto. Filósofos Portugueses do Século XVIII. Lisboa: Edições da Revista Filosofia, 1958, p. 5-36.

VERNEY, L. A. O Verdadeiro Método de Estudar. V.1 (Cartas I-IV). Lisboa: Sá da Costa, 1949.

VERNEY, L. A. 0 Verdadeiro Método de Estudar. V.3. (Cartas VIII-XI). Lisboa: Sá da Costa, 1950. 